https://doi.org/10.31470/2706-7904-2020-15-160-163

\title{
PSYCHOLOGICAL ASPECTS OF TRANSLATION
}

Психологічні аспекти перекладу

\author{
Tetiana Leleka \\ Ph.D. in Philology, Associate Professor \\ Volodymyr Vynnychenko Central Ukrainian \\ State Pedagogical University (Ukraine) \\ tleleka7@gmail.com \\ https://orcid.org/0000-0002-6134-4435
}

\begin{abstract}
The theses reveal the problem of the connection between psychology and linguistics on the basis of translation activities. The role of the human factor of a translator is revealed, and the bonds between the type of translation and the characteristics of the person who does it is established For this purpose, a psycholinguistic experiment was carried out with the participation of 50 people to demonstrate the dependence of the psychological characteristics of the translator and the quality of the translated text using comparative analysis of translation. The data has confirmed the hypothesis about psychological phenomenon of translation.
\end{abstract}

Key words: psychological experiment, translation, translation activities, comparative analysis of translation.

\section{Introduction}

Translation in its most intimate part is a psychological process. Therefore, the identification of the psychological basis of the translation is a necessary prerequisite for understanding its essence. Whereas the object of psycholinguistics is speech activity, and the object of translation theory is a special type of it, the tasks of these disciplines are largely overlapped.

Psycholinguistic turn in the study of language coincided with the attempts to expose the procedural essence of translation as a form of interlinguistic, interpersonal and intercultural communication and inevitably turned researchers attention towards experimental methods capable of lifting a lid off a notorious «black box» of the translator's mind (Jones, 2007: 63). 
The aim of the study is to establish the influence of the psychological characteristics of the translator on the quality of the translation. For this, the work set the following tasks: to describe the psychological nature of the linguistic phenomenon, to establish a connection between the type of temperament of the translator and his activity using psychological and linguistic experiments, to test the hypothesis about the impact of the psychological characteristics of the translator on his work.

While translating texts, the translator should exercise great care, since any inaccurate choice may result in the target text reader's inability to attain an adequate aesthetic response. The broader the areas of author's overlapping and translator's individual mental spaces are, the more successful the translation is (Aitchison, 1994: 95).

\section{Methods and Technics of the Research}

An important research method in translation linguistics is the comparative analysis of translation, the analysis of the form and content of the translated text in comparison with the form and content of the original. These texts are objective facts available for observation and analysis. During the translation process, a certain relationship is established between two texts in different languages (the original text and the translated text) (Kussmaul, 1995: 87). Comparing such texts, it is possible to reveal the internal mechanism of translation, identify equivalent units, and also detect changes in form and content that occur when the original unit is replaced by an equivalent unit of the translation text.

The methods of psychodiagnostics have also been used, which helped to form the psychological characteristics of the translator personality. The use of a formalized technique, namely tests, makes it possible to collect diagnostic information in a short time and qualitatively compare the individual with other people.

The third-year students of the Faculty of Foreign Languages were involved in psycholinguistic research.

Our experiment consisted of presenting a group of students with the same text for translation and three psychological techniques aimed at determining the basic personal characteristics of a person.

The attention is focused on the specifics of the translator's decision making that falls under the general definition of this process as the ability of humans to choose between competing courses of action based on the relative value of their consequences (Balleine, 2007: 8159).

We divided all received translations into free, adequate and literal, and the authors into: (a) literalists; (b) authors of free translations; (c) authors of adequate translations. 
According to these criteria 50 translation works were distributed as follows: free -26 , adequate -20 , literal -4 .

The test results also divided the translators into groups according to their psychological characteristics. Then the generalization of the personalities of each group distinguished by the quality of translation has been carried out and the calculation of the average group indicators for each psychological attribute has been done.

\section{Results}

From the obtained distribution it follows that the tendency towards literal translation is expressed minimally. There are the consequences: on the one hand, a fairly high level of teaching the theory of translation and practical translation disciplines among students, on the other hand, the disinclination of a modern person to completely abandon his own personal position. This assumption has been confirmed by the fact that none of the groups of translators showed low results on self-assessment factors. Literal translators tend to have lower self-esteem compared to other groups.

Statistically significant differences have been found between groups of translators. The result is fundamentally opposite to the generally accepted opinion that the higher the level of the translator's intellectual development, the better the translation created by him will be, and it makes us assert that the translator's intellect is not the only and not the main factor influencing the adequacy of the literary translation he creates.

The personality type of a freelance translator is an extrovert, sensory, irrational, and static. A group of adequate translators has been shown by personality type: extrovert, intuitive, irrational, and static. Average literal personality type is introvert, intuitive, irrational, and static. The particular attention has been drawn to the presence of the characteristic irrationality in all three groups. This suggests that the translation specialty, regardless of the propensity for one type of translation or another, is chosen by people with a dominant emotional principle, who are subordinate to rational characteristics.

None of the groups has showed a clear trend towards a particular style of thinking, since most of the indicators were located within the zone of uncertainty. Nevertheless, there are certain differences between the groups. Thus, freelance translators tend to ignore the pragmatic style and prefer the analytical and idealistic; adequate translators use all the styles more evenly, choosing analysis and realism a little more often than others; literalists, on the other hand, prefer realism, and use analysis and idealism less often than others.

The work of a translator is a complex profession that requires multilateral training and deep comprehension. To study the theory of this type of human activity, it is necessary to master the basics of knowledge of the most diverse scientific areas - psychology, 
philosophy, literary criticism, general linguistics, psycholinguistics, as well as, of course, those languages from which and into which translation is carried out. This statement can be attributed not only to theorists, but also to the practice of translation. This is the only way a translator will be able to consciously create and, if necessary, prove the correctness of the exact version of the translation that was offered to him.

The status of the linguistic personality of a translator is a rather complex psycholinguistic formation, the foundation of which is the personality of this specialist.

\section{Conclusions}

(1). The quality of the result of translation work is influenced not only by the level of language proficiency, the breadth of horizons and the depth of special theoretical knowledge and practical skills in translation, but also, the personal qualities of the translator: the characteristics of his temperament, attention, perception, thinking, life experience, worldview, individual and personal qualities, etc.

(2). The hypostasis of translation is, in our opinion, the procedural nature of translation, that is, intrapersonal changes that occur in the translator from the moment of acquaintance with the original until the release of the final version of the translated text.

(3). Psycholinguistics and translation theory have common points of contact. The object of psycholinguistics is speech activity, and the object of the theory of translation is a specific type of speech activity - translation. Consequently, the tasks of these disciplines are largely similar. Psycholinguistic data influence on the mechanisms of generation and perception of a speech utterance, on the structure of speech action and on the models of linguistic ability that are quite applicable to the theory of translation.

\section{References}

Aitchison, J. (1994). Words in the Mind. An Introduction to the Mental Lexicon. Oxford: Blackwell. Balleine, B.W. (2007). The Neural Basis of Choice and Decision Making. Journal of Neuroscience, 27, 8159-8160. https://doi.org/10.1523/JNEUROSCI.1939-07.2007

Jones, F.R. (2006/2007). Unlocking the Black Box: Researching Poetry Translation Processes. In E.Loffredo, \& M. Perteghella (Eds.), Translation and Creativity. Perspectives on Creative Writing and Translation Studies (pp. 59-74). London: Continuum

Kussmaul, P. (1995). Training the Translator. Amsterdam-Philadelphia: John Benjamins Publishing Company.

Zasyekin, S. (2004). Psychosemantic Aspects of Translation of Literary Texts. Book of Abstracts.

7th Congress of International Society of Applied Psycholinguistics (ISAPL), (pp. 125-126).

Cieszyn: University of Silesia. 